\title{
Exploring Learners' Perception on Improving Their Willingness to Communicate in English through Experiential Learning among Undergraduate Students
}

\author{
Siti Nadhirah Abd Rahman ${ }^{1}$, Arshad Abd Samad ${ }^{1, *}$, Norlida Abu Bakar ${ }^{2}$ \\ ${ }^{1}$ Faculty of Educational Studies, Universiti Putra Malaysia, Malaysia \\ ${ }^{2}$ Centre for the Advancement of Language Competence, Universiti Putra Malaysia, Malaysia
}

Received October 27, 2019; Revised December 2, 2019; Accepted December 24, 2019

Copyright $\subseteq 2020$ by authors, all rights reserved. Authors agree that this article remains permanently open access under the terms of the Creative Commons Attribution License 4.0 International License

\begin{abstract}
The purpose of this study is to explore the expectations and goals of students when participating in language activities, and how they perceive their willingness to communicate. The language activities involved in this study are LAX activities which are compulsory for all undergraduate students within this institution. Throughout the LAX activities, the students go through a form of experiential learning where they will have to complete a task, reflect on their work, and apply what they have learned. The students are interviewed regarding their expectations and goals prior to doing the language activities and their willingness to communicate during and after having done the activities. The findings show that students did set up positive goals before participating in the language activities, but they had negative expectations of the experience. It was also found that the students perceive an improvement in their willingness to communicate after participating in the activities. In the future, experiential learning could be implemented in language learning for positive outcomes, and more studies can be done on the topic to improve second language learning.
\end{abstract}

Keywords Willingness to Communicate, Experiential Learning, Language Activities

\section{Introduction}

The Malaysia Education Blueprint 2013-2025 has highlighted the "six key attributes needed by students to be globally competitive; knowledge, thinking skills, leadership skills, bilingual proficiency, ethics and spirituality, and national identity" [1]. Most of these attributes emphasize on the need for students to be able to communicate with others effectively. Communication is seen as a vital aspect in making Malaysian learners globally competitive. The Common European Framework of Reference for languages, which currently acts as a guideline for language teaching and learning in Malaysia, also places emphasis on communicative competence because students should be learning language for the purpose of using it in communicative situations [2].

There is a constantly increasing demand for people worldwide to communicate effectively in English, therefore the responsibility of English language teachers significantly increases [3]. Teachers have to focus not only on providing linguistic knowledge, but also on how to use language appropriately. Providing a good balance of these two aspects of language in the classroom is proven to be quite difficult, as Yang and Rehner[4] found that language learning in the second language classroom does not provide much opportunity for the improvement of communicative competence, as the content is usually not representative of authentic interaction. Therefore, language learners need to be provided with an environment where they might be willing to communicate using authentic and meaningful language to improve their communicative competence.

Communicative competence is defined as competence which allows language users to express and understand language and to construct meanings with other interlocutors within a specific context [5]. Communicative competence does not merely refer to having linguistic competence, but also knowing when and how to communicate functionally and interactively. Michael Canale categorised the elements under communicative competence as grammatical competence, discourse competence, sociolinguistic competence, and strategic competence [6]. The first two components are related to the linguistic knowledge, while the latter refers to the functional aspect of communication. 
According to Berns[7], textbooks claiming to comprise of language that is functional are often insufficient and misrepresent language used in real life interaction. Berns also mentioned the importance of context in giving meaning to form and function, especially because an understanding of function does not necessarily represent an understanding and application of the language in an authentic situation. There are certain 'rules' that govern conversations, which cannot be learnt from books and must be experienced by the learner in an authentic and meaningful way. These rules include attention getting, topic nomination, topic development, turn-taking, topic clarification, repair, shifting and avoidance, interruptions, and topic termination [8]. There are many other aspects of language that need to be taken into consideration, and cannot simply be taught with a textbook, such as pragmatics, genre, and discourse styles. These require the learner to experience communication with other parties.

It is therefore vital for the teaching and learning of English as a second language in Malaysia to focus on the aspect of communication. In order to achieve communicative competence, learners must have willingness to communicate (WTC). Willingness to communicate is the "underlying continuum representing the predisposition toward or away from communicating, given the choice" [9, p.538]. In other words, when given a choice, a language learner who has willingness to communicate will use the target language.

Sometimes teachers fail to provide a safe environment for learners and this could be because learners would distort their interaction to suit what they think the teacher wants to hear [10]. Experiential learning can provide students with a safe space to use the language in completing a task. It allows for instances where students participate in the learning through meaningful experiences rather than through the traditional approach [11].

In their study, Alqahtani[12] found that learners' willingness to communicate in English is heavily influenced by their motivation, as well as social and cultural factors. Malaysian students are often unwilling to communicate due to fear of receiving a negative response [13]. A number of studies have been done on willingness to communicate, but limited studies have especially been done in relation to the implementation of experiential learning for language learning. It is vital for a study to be done to see how Malaysian students perceive their willingness to communicate in order to understand how to improve their language learning experience.

The purpose of this study is to explore the expectations and goals of students when participating in language activities, and how they perceive their willingness to communicate. The research questions to be answered with this study are listed below:

RQ1: What are students' expectations and goals when participating in the language activities?

RQ2: How do students perceive their willingness to communicate (WTC) through participation of the language activities?

\section{Review of Literature}

Malaysian students are known to have issues with speaking, or any communicative activities in general when it comes to the English language. This relates to their willingness to communicate when faced with communicative activities in the classroom.

\subsection{Willingness to Communicate (WTC)}

Research has found that there are six layers of factors that have an influence on language learners' willingness to communicate [14]. These factors can be divided into enduring influences, which are somewhat permanent to a person, and situational influences, which depend on the situation. The six layers are communication behaviour, behavioral intention, situation antecedents, motivational propensities, affective-cognitive context, and social and individual context [14]. Referring to the figure below, the top three layers are situational influences, while the three bottom layers are enduring influences, which have a more significant effect on a learners' willingness to communicate.

Willingness to communicate has little to do with speaking abilities, rather it is more heavily influenced by affective factors such as motivation, personality, intergroup climate and self-confidence [9]. Self-confidence can refer to situational self-esteem and also L2 self-confidence, which does not depend on the situation [8]. Some language learners' self-confidence could have been formed based on prior experience with language learning, due to communicative competence and lack of [14]. Some situational factors such as the number of participants, topic and formality of the conversation could also impact second language learners [15] 


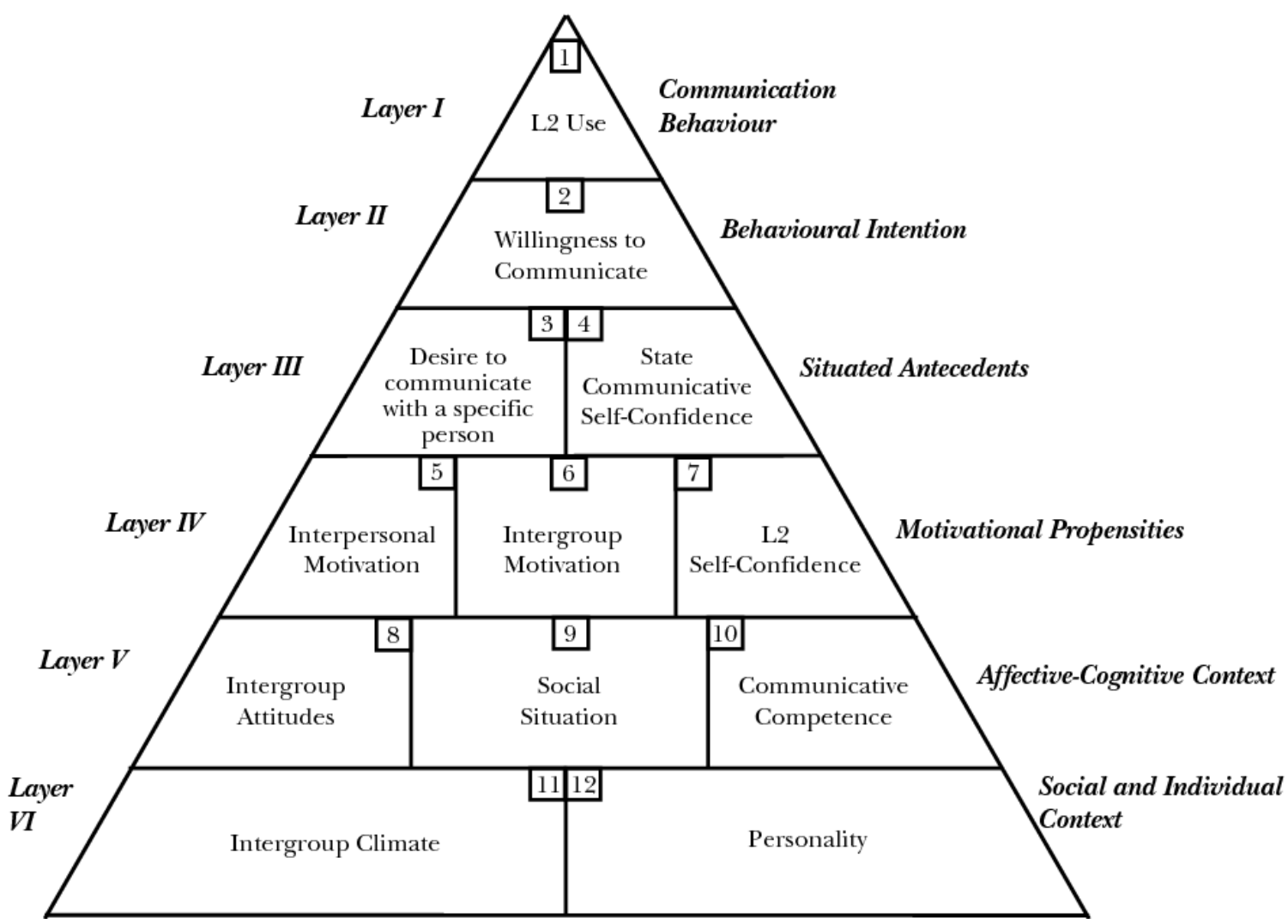

Figure 1. Willingness to Communicate Model

Syed and Kuzborska[16] found that numerous contextual, psychological, linguistic and physiological factors have an influence on learners' willingness to communicate, with contextual factors having the biggest impact. A study on Malaysian learners found that they are unwilling to speak the target language because they lack familiarity with the vocabulary and lack of confidence due to low proficiency [13].

A study by Alikhani and Bagheridoust[17] found that having group activities in a language classroom improves learners' willingness to communicate, as the activities sparked the learners' interest and motivation. Vosburg[18] found that learners were unwilling to speak the target language when other group members lacked interest and motivation in learning and participating in the group activity. In a related study, interest, perceived effectiveness, groupmates' commitment, social atmosphere, personal goal, self-confidence and marks were revealed to play a role in motivating English language learners in Macau to participate in group tasks [19].

\subsection{Experiential Learning}

This study refers to Kolb's[20] model for experiential learning, where learning is seen as process, is grounded within experience, includes adapting to the world, needs a resolution or conflict, happens through interaction and is knowledge creation. People interact with the environment to grasp information and transform the information they acquired; concrete experience and abstract conceptualisation are the sources of information, while reflective observation and active experimentation are processes for transforming information. The cycle for experiential learning is shown in the figure below.

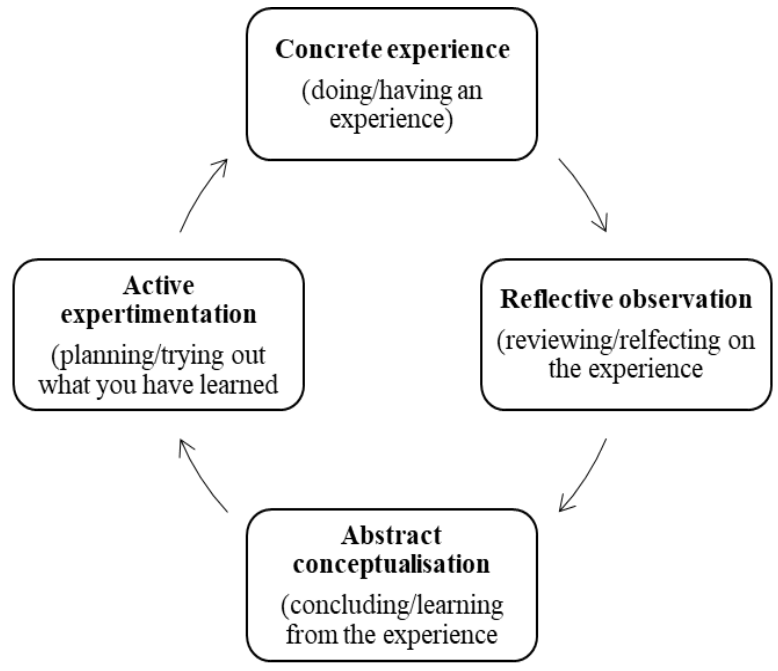

Figure 2. Experiential Learning Model

With the rise in experiential learning, Kisfalvi and Oliver[10] suggest that experiential learning can provide learners with a safe space which involves trust, respect, restriction of judgment, readiness to share and effective listening. Knutson[11] refers to experiential learning as an 
investment in boosting motivation, self-perception and confidence, and practical skills unrelated to language learning.

Experiential learning can help students in following complex materials, retaining knowledge, practicing the skills that they have learned and understanding group work [21]. Within the context of language learning, experiential learning can provide meaning and purpose to lessons while making it interesting for the learners as well [22]. The study also found that learners could be more autonomous and creative with experiential learning. In another study, the learners felt that the experiential learning process helped with their anxiety, improved their self-confidence and improved their motivation in language learning [23].

\section{Method}

A qualitative research design has been chosen for this study as an activity such as this is the first of its kind in a local research university, therefore it is important for an exploratory study to be done in order to appropriately describe the perspectives of the language learners [24]. Limited studies have been done on the implementation of experiential learning to improve willingness to communicate that provides a strong basis for this study to explore the issue. Three undergraduate students were chosen using purposive sampling based on the informant criteria that were decided at the beginning of the study.

According to Allen[25], it is especially important for a list of criteria to be decided on before looking for informants as to decide who would be most appropriate for this study. The students needed to be undergraduate students who have completed their Language Activities or LAX requirements, as they would be able to provide an extensive and clear description of their experience and feelings with regards to their willingness to communicate.

The current study that employed in-depth interview was chosen for this study so as to provide the participants with a space to express their thoughts without being restricted by the presence of others and reveal the social, cultural and psychological factors influencing them [26]. Participants were asked questions on their personalities, trait-level characteristics and situation-based characteristics in relation to their willingness to communicate. A semi-structured interview guide was prepared prior to the first interview session, and improved after getting responses from the first participant and coding the transcription. Preliminary coding is done with each participant in order to document researchers' thoughts and any extra remarks [27]. Participants were interviewed until a saturation point was reached. Coding was done using ATLAS.ti. The codes was formed into categories, then grouped into themes according to the research questions.

The language activities that will be addressed in this study are LAX activities that provide a safe environment for students to continuously engage with the language. LAX activities are divided into 6-point LAX and 12-point LAX, which differ based on the number of weeks in which students need to be engaged in the activities. There are a number of different activities that students can choose from which require them to interact and work in groups in order to complete specific tasks.

Students will first go through a discussion session for them to share ideas and make decisions, and a reflection session where they talk about what they have done well and what they could improve on. After that, they are usually given one or two opportunities to produce another product and improve based on the shortcomings they found in their first product. They go through the same process of discussion, execution and reflection.

This provides students a seemingly safe environment, where they are surrounded only by peers. Throughout the whole process, they engage with the language freely without much restriction, boosting their self-confidence and fluency. For ease of description and understanding, the LAX activities will be referred to as language activities throughout this paper.

\section{Results \& Discussion}

The data are analysed and discussed based on the research questions.

\subsection{RQ1: What Are Students' Expectations and Goals When Participating in the Language Activities?}

It was found that the students mostly had negative expectations of the language activities before actually participating in them. One student expected that they would have difficulty with groupmates, while another student mentioned that they expected that the language activity would mean more work for them to do. Student C was scared to join the language activity due to lack of confidence in her proficiency. Student A and B expressed that they also had positive expectations of the language activities, especially in terms of improving their fluency. Student A stated "I expect from the LAX can make me fluent in English communication".

When asked about their goals when participating in the language activities, two of them stated that they want to improve their English for the purpose of communicating with others. Student C mentioned that this goal is what helps motivate her to participate in the language activities, "Because I have goal to improve my English, sometime I will be motivated more".

Student A also expressed his goal to make new friends, while student B stated that her only goal was to complete the LAX so that she could feel relieved.

The findings for the first research question show that these students mostly have negative expectations towards 
the language activities, and this could be due to their past experiences. Negative past experiences especially with group work could influence their view on the activities [11]. The positive goals, namely those related to language learning can be interpreted as their desire to improve their willingness to communicate. These expectations and goals can have an impact on their willingness to communicate, as it could become a motivating or demotivating factor for them to communicate in the target language.

\subsection{RQ2: How Do Students Perceive Their Willingness to Communicate (WTC) through Participation of the Language Activities?}

The current study has revealed that all the students felt that their willingness to communicate outside the classroom had improved after participating in the language activities. Student $\mathrm{C}$ expressed her thoughts, "I think yes, because compare my English to when I was in first sem and now, I think now is just more better. Yeah, because when I was in my first sem, I was not confident at all to speak in English so now I feel I can talk little bit”.

This research question is discussed in relation to the contributors to students' willingness to communicate, with reference to the pyramid model [9] as well as other previous studies on willingness to communicate and experiential learning.

\subsubsection{Group Attitude}

Throughout the three interviews, groupmates were seen to have a significant influence on the students' perception of the language activity. When students are familiar with their groupmates or they get groupmates who are easy to work with, they tend to be more motivated to participate in the language activity. Student $C$ stated her thoughts, "I enjoy the most with my groupmates ... because all of them are very sporting ... I can easily gather and discuss with them"

Vice versa, having a negative experience with groupmates can also have an undesirable outcome on the students' motivation. Student A mentioned his experience with some groupmates who cause issues due to time constraint, "I think they don't want to go to meeting to discuss with the friend because they don't have time to, they want arrange time to meet together".

Aside from the issue with time, some students highlighted the issue with choosing a location to meet. This became a demotivating factor because these students from different faculties and living in different residential colleges had to decide on a location that would be easily accessible to all groupmates. Student B described her experience, "So their college is quite far from me ... and I am the one and only from Kolej Lembah, K5 at that time and I have difficult to meet them and I still remember I met them after maghrib at main library".

A study on implementation of group activities in language learning found that students have a positive perception towards the atmosphere created [17]. This coincides with the findings of the current study, where all the students expressed that they were more motivated to do activities in their group, but only when the groupmates were easy to work with and within close proximity. Familiarity is seen as a vital aspect in another study as well, where Vosburg[18] found that when students feel interconnected with other groupmates, they are more willing to communicate in the target language. Similarly, uncommon interests can also cause students to be demotivated, as shown in the same study. Eddy-U[19] also found that the group members' participation and motivation during the activity can have a huge impact on the motivation level of a student.

\subsubsection{Personality during the Language Activities}

Student B and C stated that they were relaxed during most of the language activities, except those which they had issues with groupmates, with student B mentioning that she is commonly talkative during the discussions. Student A mentioned that he is quite shy and does not speak much during the language activities. In comparison to their personality outside, student B claims that she is as talkative outside the language activity as she is in it.

As for student $\mathrm{A}$ and $\mathrm{C}$, it depends on the situation and who they are around. All the students said that they are usually comfortable to speak using the target language even outside the language activity. Student A mentioned that this is because there is no form of supervision by an instructor or lecturer, and the communication is only with the other person. Student B also shared her thoughts, “... because foreigner student use simple words, so I'm also can understand them and I'm also use simple language for them"

The responses from this study go against the research that found some students to be more willing to speak during group activities as opposed to when they are expected to produce the language individually [17]. In this study, personality is seen as a stable trait where learners maintain the same personality during language activities as they do in other situations. A study on Iranian students found that their outgoing personality even outside the classroom had caused them to have a higher willingness to communicate in activities [28], coinciding with the findings of the current study.

\subsubsection{Self Confidence}

The students had different perceptions of their self-confidence during the language activities, with Student B saying that she was not scared of making mistakes and simply expressed what she wanted to say, while Student A admitted that he was not confident because he was scared to make mistakes. However, student B added that she was "not 100 percent confident" due to lack of fluency. As for student $\mathrm{C}$, she feels it depends on 
the topic, "I'm feeling very confident if the topic that we are discuss, I know more information about that".

Both student $\mathrm{B}$ and $\mathrm{C}$ expressed that the language activity did help in improving their confidence to speak in the target language. Student B also mentioned that the requirement of one of the activities, where the students need to interact with random people, had tremendously improved her self-confidence when talking to strangers. She also gave an example of a situation where this newfound confidence had helped her in communicating with bank personnel, "And I'm listening what the staff said and I can respond in English too, so I have confident, that confidence actually of course from LAX activities".

These responses show that self-confidence can be a trait-level characteristic as shown by Student B, where she is confident to speak during the language activity because she is a generally confident person. This goes back to personality, which has been described in the prior section. However, there are also people like Student C, whose confidence varies depending on the topic which is discussed, which could point to her self-confidence being dependent on the situation. In relation to this, a study found that topic is the most influential contextual variable for learners' production of a target language [16].

Similar to the situation with Student A whose confidence is affected by the fear of making mistakes, [19] found that the possibility of being ridiculed for mistakes could demotivate students from using the target language, namely in group activities.

\subsubsection{Experiential Learning (The Process \& Different Activities)}

Seeing as this study is based on language activities which are based on the concept of experiential learning, the students had also been asked questions in relation to it. When asked about the whole process of the activity, which requires them to have a discussion, then execute the project, complete a reflection, then go through the cycle again, all three students had a generally positive perception of the process. They felt that it helped in providing opportunities for them to use and improve their language, which also opened spaces for sharing of ideas. Student $C$ expressed her opinion, "Of course it makes me improve my English because when discussion we want to talk in English, so it improves our English communication".

The only issue that they have with the whole process is that it is very tedious and takes up a lot of their time. Student A expressed his thoughts on this, "It very difficult because... sometime when we want to have discussion, execution and reflection, always we have meeting every week. So, for me, I don't have time for discussion".

Student B suggested that this issue be overcome if lecturers extended the duration of time given to complete each phase of the activity, "So, I think it's more easy if the lecturer, gives more deadline, more days to complete our video. So I think it is good for us".
Knutson[11] claims that experiential learning should provide students with a platform to develop the target language by using the language within a specific context as opposed to looking at the aspects of language separately. This can be reflected in the students' responses in the current study. As for the time constraint, Singaporean students also found issues with submitting before the deadline, especially due to their lack in proficiency [22]. This could be improved by proper planning by the lecturer.

Experiential learning also provides students with the opportunity to learn through a variety of activities. The different types of language activities that students need to complete have an impact on their motivation, where some activities motivate them to participate and speak more, while others have the reverse effect. Student $\mathrm{C}$ had participated in an activity where they interviewed random students on campus, "In (this activity) we have to shoot about that video where we need to be a host. So it will train us to speak confidently".

Student A mentioned that he was demotivated when doing a language activity related to poetry because he does not enjoy poetry, while Student B stated that she did not prefer activities that required her to sing, "To do the video, I'm not really enjoying because I want to speak. I don't want to sing".

When asked how he deals with topics he is unfamiliar with such poetry, Student A responded, "When this (activity), I just talk how to edit the video and then discuss, I just discuss about my problem in the edit video only".

This is supported by another study, as different topics and types of tasks that students were asked to perform had a significant impact on their willingness to communicate in a study by Syed and Kuzborska[16]. In relation to the issue of unfamiliarity, another study suggested that students are commonly willing to communicate when given a familiar topic and task [29].

Generally, the findings show that students feel their willingness to communicate has improved after participating in the language activities.

\section{Conclusions}

Clearly, the students felt that their willingness to communicate had improved after joining the language activities. All of them perceive themselves to be affected by group attitude, their personality, self-confidence and the implementation of experiential learning. Groupmates' attitude appears to have a significant influence on the students' willingness to communicate, where group members who refuse to commit and lack motivation can demotivate and even prevent students from participating altogether. It also seems to be the case that factors such as an out-going personality and self-confidence can be a permanent trait that assists their willingness to communicate, or it could also be dependent on the 
situation. The implementation of experiential learning can also have a positive or negative impact on the students' willingness to communicate.

Identifying which activities motivate students may be a difficult task, as different students would enjoy different types of tasks. However, educators can play a role in providing students with a safe environment where they can express their difficulties in performing the task, which would allow them to openly talk and reflect on the situation. This is where experiential plays an important role, as students are not restricted to talk about a certain topic, but they are asked to perform a task which needs them to communicate in order to complete the task. Aside from the deadlines, the students enjoyed and gained a lot from the experiential learning process. As for the issues with group members, perhaps a better system could be developed to prevent motivated students from being demotivated and bogged down by students who are not committed to participating in the activities.

In the future, more studies could be done on the implementation of experiential learning in language learning. Perhaps students' willingness to communicate could be studied along with their marketability and communication skills. Since quite a lot students see this learning experience as a platform for them to learn how to communicate during job interviews and for career development purposes, it would be relevant to see how this experience actually helps in achieving this.

\section{Acknowledgements}

We are very grateful to colleagues at Universiti Putra Malaysia, especially the Centre for the Advancement of Language Competence (CALC), for providing assistance and information throughout this study.

\section{REFERENCES}

[1] Ministry of Education. 2012. Malaysia Education Blueprint 2013-2025.

[2] Council of Europe. 2001. Common European Framework of Reference for languages: Learning, teaching, assessment. Online available from https://rm.coe.int/1680459f97

[3] A. Saeed, R. Congman. 2013. Applying communicative approach in teaching English as a foreign language: A case study in Pakistan. Porta Linguarum, 187-203.

[4] J. Yang, K. Rehner. 2015. Learner beliefs about sociolinguistic competence: A qualitative case study of four university second language learners. Language Learning in Higher Education, 157-180.

[5] D. Hymes. 1967. On Communicative Competence. Unpublished Manuscript. University of Pennsylvania.
[6] M. Canale. 1983. From Communicative Competence to Communicative Language Pedagogy. In J. Richards, \& R. Schmidt, Language and Communication. Longman Group.

[7] M. Berns. 1984. Review of the book 'The Functional-Notional Approach: From Theory to Practice'. TESOL Quarterly, pp. 325-329.

[8] H. D. Brown. 2007. Principles of Language Learning and Teaching. New York: Pearson Longman.

[9] P. MacIntyre, S. Baker, R. Clement, \& L. Donovan. 2002. Sex and age effects on willingness to communicate, anxiety, perceived competence, and L2 Motivation among junior high school French immersion students. Language Learning, 537-564.

[10] V. Kisfalvi, \& D. Oliver. 2015. Creating and maintaining a safe space in experiential learning. Journal of Management Education, 39 (6), 713- 740.

[11] S. Knutson. 2003. Experiential learning in second-language classrooms. TESL Canada Journal, 2 (2), 52-64.

[12] M. Alqahtani. 2015. Saudi students' willingness to communicate and success in learning English as a foreign language. Journal of Language Teaching and Research, 6 (6), 1195-1205

[13] W. Hiew. 2012. English language teaching and learning issues in Malaysia: Learners' perceptions via Facebook dialogue journal. Journal of Arts, Science \& Commerce, 3 (1), 11-19.

[14] P. MacIntyre, R. Clement, Z. Dornyei, \& K. Noels. 1998. conceptualizing willingness to communicate in a L2: A situational model of L2 confidence and affiliation. Modern Language Journal, 545-562.

[15] P.M. Lightbown, \& N. Spada. 2006. How Languages Are Learned (3rd Edition ed.). New York: Oxford University Press.

[16] H. Syed, \& I. Kuzborska. 2018. Dynamics of factors underlying willingness to communicate in a second language. The Language Learning Journal, 1-20.

[17] M. Alikhani, \& E. Bagheridoust. 2017. The effect of group dynamics-oriented instruction on developing Iranian EFL learners' speaking ability and willingness to communicate. English Language Teaching, 10 (11), 44-59.

[18] D. Vosburg. 2017. The effects of group dynamics on language learning and use in an MMOG. Computer Assisted Language Instruction Consortium (CALICO), 34 (1), 58-74.

[19] M. Eddy-U. 2015. Motivation for participation or non-participation in group tasks: A dynamic systems model of task-situated willingness to communicate. System, $43-55$

[20] D. A. Kolb. 1984. Experiential learning: Experience as the source of learning and development. Englewood Cliffs: Prentice Hall.

[21] P. L. McLeod. 2013. Experiential learning in an undergraduate course in group communication and decision making. Small Group Research, 44 (4), 360-380. 
[22] N. H. Saphari, M. A. Bakar, K. Thiru, \& T. K. Hoe. 2015. Experiential learning to enhance mother tongue languages (MTL) learning in Singapore's context among jc1 students A case study of Balestier cultural traits. People: International Journal of Social Sciences, 1 (1), 1391-1400.

[23] I. Moreno-Lopez, A. Ramos-Sellman, C. Miranda-Aldaco, \& M. Quinto. 2017. Transforming ways of enhancing foreign language acquisition in the Spanish classroom: Experiential learning approaches. Foreign Language Annals, 50 (2), 398-409.

[24] J. Creswell. 2003. Research design: Qualitative, quantitative and mixed methods approaches. California: SAGE Publications.

[25] H. B. Allen. 1971. Principles of informant selection. American Speech, 46, 47-51.

[26] Z. Dornyei. 2001. Teaching and researching motivation. England: Pearson Education.

[27] J. Saldana. 2013. The Coding Manual for Qualitative Researchers (2nd Edition ed.). London: SAGE Publications.

[28] D. Cameron. 2013. Willingness to communicate in English as a second language as a stable trait or context-influenced variable: Case studies of Iranian migrants to New Zealand. Australian Review of Applied Linguistics, 36 (2), 177-196.

[29] F. A. Sari. 2016. Enhancing EFL students' willingness to communicate: teachers' beliefs about their roles and strategies. Kajian Linguistik dan Sastra, 1 (1), 1-16. 